\title{
Measurements and prediction of fabric surface fitting ability under low tension
}

\author{
KyoungOk Kim ${ }^{1}$, Tomoya Suzuki ${ }^{2}$, Masayuki Takatera ${ }^{1^{*}}$
}

\author{
${ }^{1}$ Division of Kansei and Fashion Engineering, Institute for Fiber Engineering (IFES), Interdisciplinary Cluster for \\ Cutting Edge Research (ICCER), Shinshu University, Japan \\ ${ }^{2}$ Division of Textile \& Kansei Engineering, Graduate School of Science and Technology, Shinshu University, Japan
}

takatera@shinshu-u.ac.jp

\begin{abstract}
This study investigated the surface fitting ability of woven fabric under low tension using a new measurement method. The limit angle of shear buckling, the maximum shear angle, is defined as the surface fitting ability. To estimate the maximum shear angle, we measured the base radius of a spherical crown of woven fabrics while covering the spherical surface without wrinkles. The relationship between the maximum shear angle and base radius was calculated numerically. We constructed a new testing equipment to determine the surface fitting ability of fabric with an aluminium hemisphere set on a laboratory jack and acrylic boards with holes of varying size at the centre. Nineteen kinds of woven fabric samples and three hemispheres of different radii were used to measure the surface fitting ability. The relationships among the maximum shear angle and mechanical and structural properties were investigated. Thickness, interlacing point density and shear stiffness showed high correlation with the surface fitting ability. Using these properties, a new prediction formula for surface fitting ability was proposed. The predictive values showed a good agreement with the measured values. Therefore, the proposed method and the prediction equation are useful for evaluating the surface fitting ability of woven fabrics. The effect of the sphere radius on the surface fitting ability was also clarified.
\end{abstract}

\section{INTRODUCTION}

In comparison with other sheet materials, such as paper and film, woven fabrics can be easily deformed into threedimensional surfaces. They can be used to cover an undevelopable surface, which is a surface that cannot be flattened into a two-dimensional pattern without stretching, tearing or squeezing it. In clothing and interior textiles, undevelopable surfaces such as the bust, waist and buttock parts of a garment and car-seat should be covered by a fabric. The ability to form an undevelopable surface without wrinkles or darts is referred to as surface fitting ability in this study ${ }^{1-3}$.

For example, if a sphere, such as a watermelon, is wrapped with a cloth, the lower half can be covered without wrinkles $^{4}$ [4]. However, if it is attempted with paper, this part shows wrinkles. This is due to the different surface fitting ability between woven fabric and paper. In Figure 1, the top views show the difference clearly. Thus, in dealing with fabric for making an undevelopable surface, surface fitting ability has a great meaning.

The fitting ability is related to the good appearance of a garment without wrinkles. Relating to garment tailoring, the ability of fabric deformation is called the making-up property, tailorability or formability ${ }^{5-7}$. Many researchers have investigated the relationships between these properties and the mechanical properties of fabric. Lindberg et al. ${ }^{5}$ and Waesterberg ${ }^{6}$ investigated the relationship between the making-up properties of several wool fabrics and the mechanical properties of fabrics such as tensile strain, bending stiffness and shearing. Morooka and $\mathrm{Niwa}^{7}$, Shishoo ${ }^{8}$, and Kawabata and $\mathrm{Niwa}^{9}$ investigated the factors that contribute to the making-up properties and a good appearance in finished garments by measuring the mechanical properties of fabrics, such as extension, bending, shearing, compression, and surface friction. Mahar et al. ${ }^{10-12}$ nd Bassett et al. ${ }^{13-14}$ also investigated the relationship between those properties and clothing manufacturing.

The reasons for the varying fitting abilities of woven fabric are as follows ${ }^{1}: 1$ ) shear deformation between warp and weft at various degrees; and 2) extension and contraction in the yarn direction. This study focuses on the covering property relating to shearing of a fabric. It is believed that the fitting ability of woven fabric is superior to that of other sheet-like objects, such as paper, because the critical angle of the fabric caused by shear deformation is much larger than that of other sheet-like objects ${ }^{15}$.

Covering spherical surfaces is a simple way to understand the fitting ability, so it has been investigated theoretically and experimentally by many researchers. Mack and Taylor ${ }^{16}$, Heisey et al. ${ }^{17}$, Shinohara and Uchida ${ }^{2}$ [2] and Moriguchi and Sato ${ }^{4}$ have investigated the fitting equations for fabric to spherical surfaces based on the shear behavior of woven fabric. Takatera et al. ${ }^{18}$ investigated sphere surface construction using a polyhedron made of woven fabric. Shinohara and $\mathrm{BaO}^{19}$ proposed a new method to cover a sphere with a pleated rectangular fabric.

When a woven fabric covers a sphere, the shear angle reaches the limit of shear deformation; then, wrinkles occur because of shear buckling ${ }^{20}$. In the shear test, a shear buckling wrinkling is observed. However, the first appearance is 
highly subjective ${ }^{20}$, and many fabrics do not show wrinkling in the ordinary shear strain range of the test. Bassett ${ }^{13}$ investigated the fitting ability using a model consisting of a net-like grid of rigid rod elements. By fitting to a sphere surface, the effect of external load on the limited angle of a smooth surface was calculated. However, the prediction method requires a special shear tester and the verification under low load is not carried out. Therefore, simple and easy measurement and prediction method is still necessary. Ayada et al. ${ }^{21}$ proposed a method of evaluating the fitting ability using a sphere and painted cloth. A sample cloth covers the sphere, applying a weight. By confirming the transferred paint shape on the sample cloth, the fitting ability is evaluated. Ayada ${ }^{22}$ also investigated the relationship between fitting ability and mechanical properties of fabrics and proposed a prediction equation for the fitting ability using the shear, bending and tensile properties of a fabric. However, the measuring method is difficult and time-consuming. In addition, the relational equations between fitting ability and physical properties are complex, and the physical meaning is unclear.

Therefore, a method of quantitatively evaluating the surface fitting ability, based on the index of the shear angle when covering the actual curved surface, is necessary. If the fitting ability of a fabric can be predicted, manufacturers will be able to select suitable fabric efficiently. Furthermore, if the factors that affect the fitting ability and the relations were understand, prediction of the fitting ability will be possible by performing a calculation on the basis of existing indicators. Thus, the purpose of this study is to establish a method of quantitatively evaluating and predicting the surface fitting ability.

In this study, evaluation of the fabric fitting ability was carried out by measuring the shear limit of fabric. The relationship among the obtained fitting ability of fabric, physical properties such as shear and bending properties, and the fabric structure were investigated. Then, prediction equations of fitting ability using the mechanical and structural properties of the fabric were proposed.

Furthermore, if fabric thickness is ignored, the diameter of the sphere would not affect the fitting ability of fabric. Ayada et al. ${ }^{21}$ also mentioned that the sphere size does not affect the fitting ability. However, the shear strain is distributed on the whole fabric under low tension, so the diameter of the sphere may affect the fitting ability. Thus, the effect of sphere diameter on fitting ability is also investigated in this study.
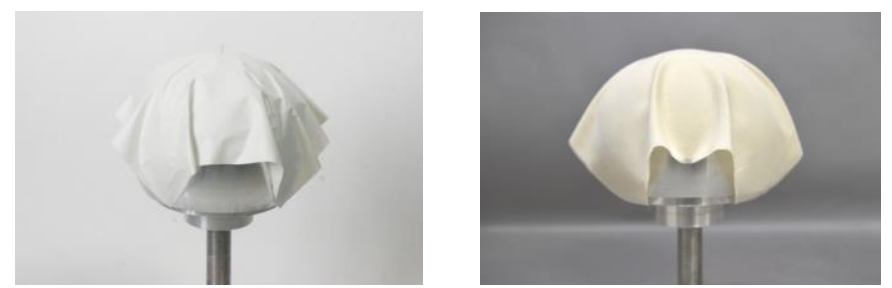

(a) paper (side view)

(b) woven fabric (side view)
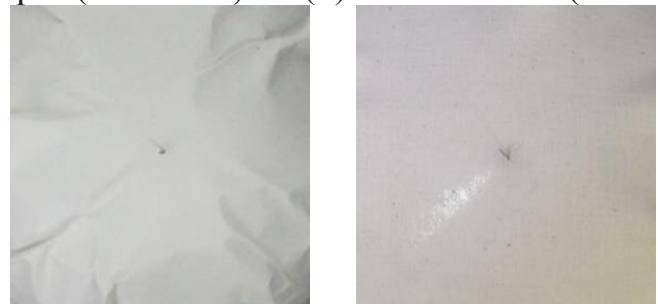

(c) paper (top view)

(d) woven fabric (top view)

Figure 1. Comparison of fitting ability of paper and woven fabric.

\section{Theoretical}

The covering property of fabrics for a spherical surface was investigated. The deformation limit of a fabric covering a spherical surface without wrinkling when no external tensile load is applied as an index of surface fitting ability was regarded.

Shear angle and the coordinates on a sphere of radius $R$ were determined by numerical calculation by assuming a fabric as a lattice which undergoes shear deformation, as shown in Figure 2. It was assumed that the warp and weft is not extended. Warp and weft that pass through the centre of the lattice are put on the meridians of the sphere that are perpendicular at the pole. The position of the lattice points on the sphere from the pole was determined. Lattice points were set by dividing the warp and weft at regular intervals.

The intersection angle $\varphi$ between the warp and weft of the fabric becomes sharpest in the bias direction of the fabric. Shear angle $\theta$ is the complementary angle of $\varphi$, as shown in Figure 2. $\theta_{45}$ is defined as the shear angle in the bias direction. We assumed that a wrinkle appears when $\theta_{45}$ exceeds a critical angle of the shear of the fabric. We denote the maximum shear angle of fabric covering a spherical crown without wrinkling in the bias direction by $\theta_{\max }$ and introduce it as an index of surface fitting ability. Shinohara and $\mathrm{Uchida}^{2}$ showed a differential equation of fabric shear deformation for covering a spherical surface and obtained an approximated solution of the equation. For our experiment, we 
numerically calculate the coordinates of deformed fabric ${ }^{23}$ and obtained the relationship between shear angle and the coordinates. Figure 3 shows the geometrical parameters of a sphere, where the base radius $r$ is the distance between the central vertical axis and the point, $a$ is the arc length from the top of the sphere to the point and $\psi$ is a polar angle. Figure 4 shows the relationship between $r / R$ and $\theta_{45}$. Ayada et al. ${ }^{21}$ evaluated the fitting ability using $a / R$ experimentally. $a / R$ is equal to $\psi$ and given by $\sin ^{-1}(r / R)$. Figure 5 shows developed patterns in a plane of $X$ and $Y$ coordinates for each quarter spherical crown for different polar angles. As shown in Figure 5, when the polar angle is small, the developed pattern shows a shape similar to a circle and when it is large, the pattern shows a shape similar to a square. Figure 6 shows the relationship between shrinkage of the contour line of the pattern when it fits to the parallel of the sphere and polar angle. When the polar angle is under 5 degrees, the shrinkage is close to 0 . When it is approximately 50 degrees, the shrinkage becomes approximately $0.10(10 \%)$ which is required for sleeve cap easing ${ }^{24}$.

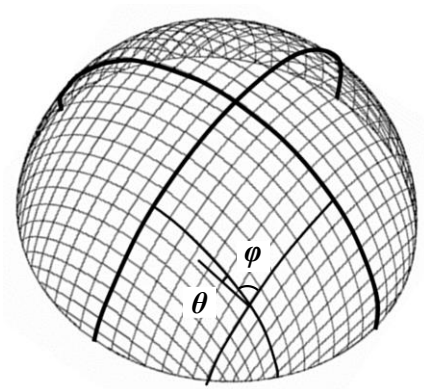

Figure 2. An isometric view of a half sphere and illustration of determination of shear angle $\theta$.

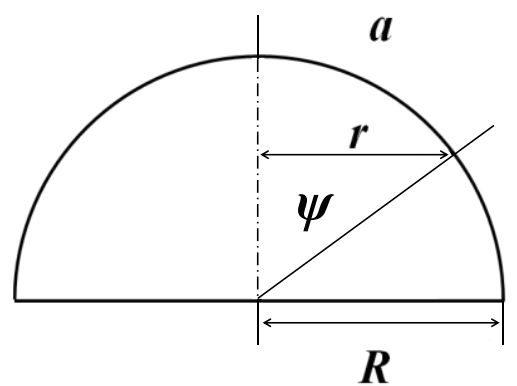

Figure 3. An orthographic view of a half sphere with dimensions of $R, r$ and $a$ on a sphere.

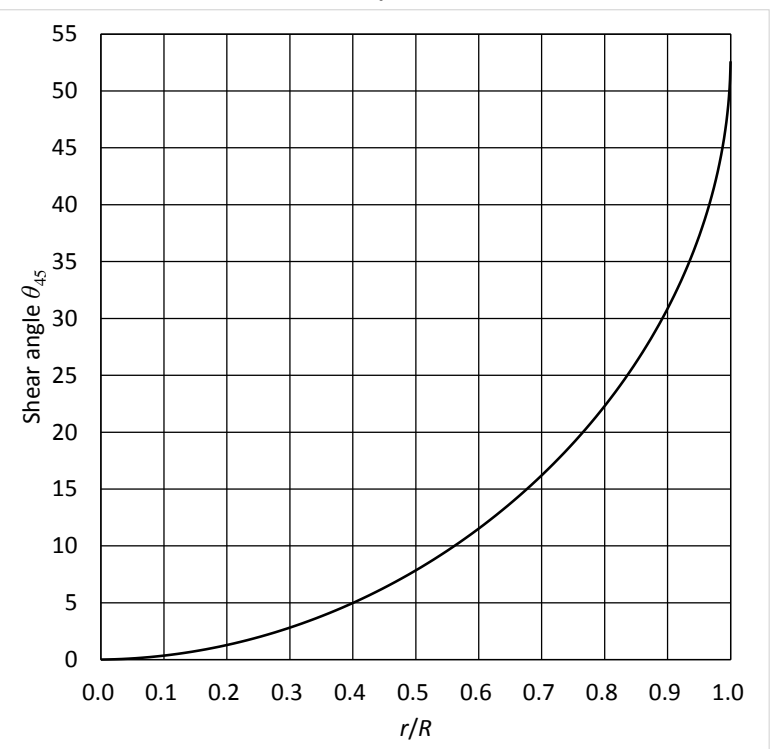

Figure 4. Relationship between $r / R$ and $\theta_{45}$. 


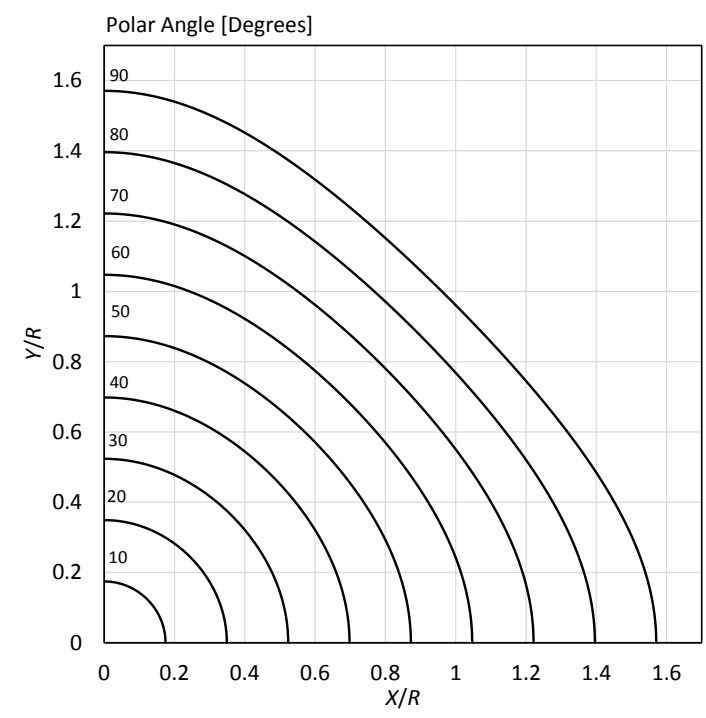

Figure 5. Pattern of quarter spherical crown for different polar angles.

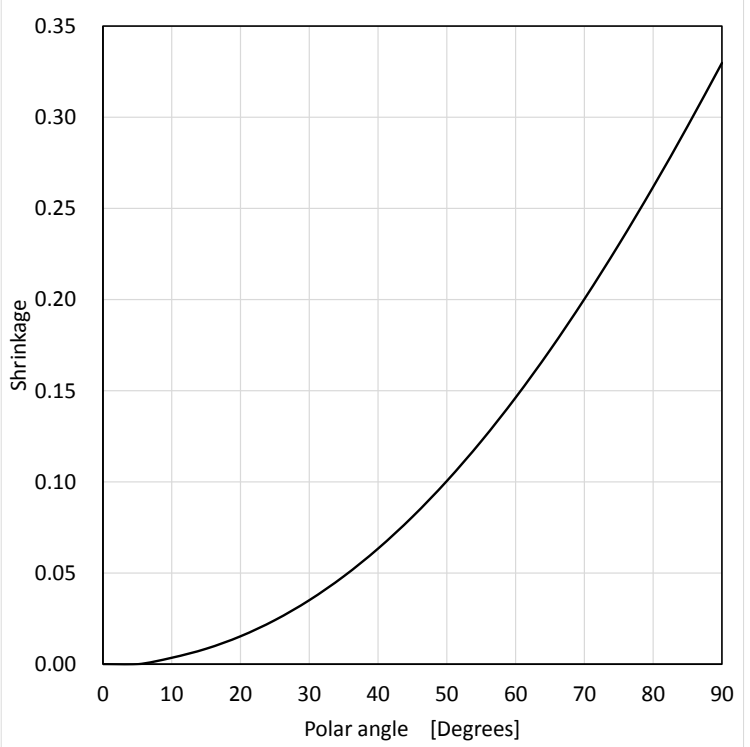

Figure 6. Relation between shrinkage of contour line and polar angle.

\section{EXPERIMENTAL}

\section{Measurement of surface fitting ability of fabric}

New equipment to measure the largest base radius $r_{\max }$ of a spherical crown when sample fabric covers the sphere without wrinkling was constructed. To measure $r_{\max }$, we used a hemisphere and plates with circular holes of varying radii. Figure 7 shows a schematic diagram of the experimental equipment. One hemisphere was set on a stand, and the hemisphere and stand were placed on a laboratory jack so that they could be moved up and down. The equipment was set in a frame, allowing placement of the acrylic board.

Three aluminium hemispheres of radius $R=63,75$ and $100 \mathrm{~mm}$ were prepared to confirm the effect of the radius of the sphere. Acrylic boards with thicknesses of $3 \mathrm{~mm}$ with holes of different radii were made. The radii of the holes corresponded to 1-degree intervals of critical shear angle $\theta_{45}$ from 1 to 30 degrees for hemispheres of radius $R=75$ and $100 \mathrm{~mm}$, as shown in Appendix 1. For the hemisphere of radius $R=63 \mathrm{~mm}$, those boards and corresponding values of critical shear angle shown in Appendix 2 were used.

Figure 8 shows the measurement procedure using the equipment. In the measurement, a square of sample fabric was placed over the sphere with the central warp and weft of the fabric corresponding to the perpendicular meridians. The four mid-points of each fabric edge were fixed with adhesive tape to keep the central yarns perpendicular. Each acrylic board was horizontally set on the equipment frame with the centre of its hole coinciding with the centre of the sphere. The sphere was raised by the laboratory jack, and we checked for wrinkling on the spherical crown as shown in Figure 9. This work was repeated, starting with the acrylic board having the smallest hole and then replacing it with acrylic boards having increasingly large holes, until wrinkling first appeared, at which time the corresponding $\theta_{45}$ as 
the $\theta_{\max }$ of a fabric was recorded. All the same procedures were used for all three hemispheres. The experiment was performed five times for each sample fabric and took the mean value for the analysis of results. Because there was no differences according to the sample size in preliminary experiment, $300 \mathrm{~mm} \times 300 \mathrm{~mm}$ samples were used for all hemispheres. The experiment was performed at $20 \pm 1{ }^{\circ} \mathrm{C}$ and $65 \% \pm 5 \%$ relative humidity after preconditioning for 24 hours at the same condition.
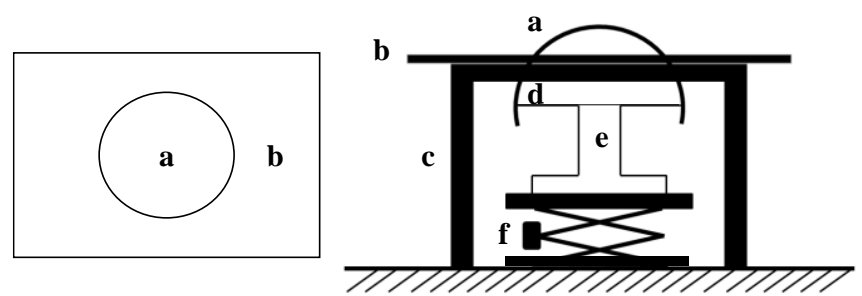

$$
\begin{aligned}
& a: \text { sample } \\
& b: \text { acrylic board } \\
& c: \text { frame } \\
& d: \text { hemisphere } \\
& e: \text { stand } \\
& f: \text { laboratory jack }
\end{aligned}
$$

Figure 7. Schematic diagram of the experimental equipment.
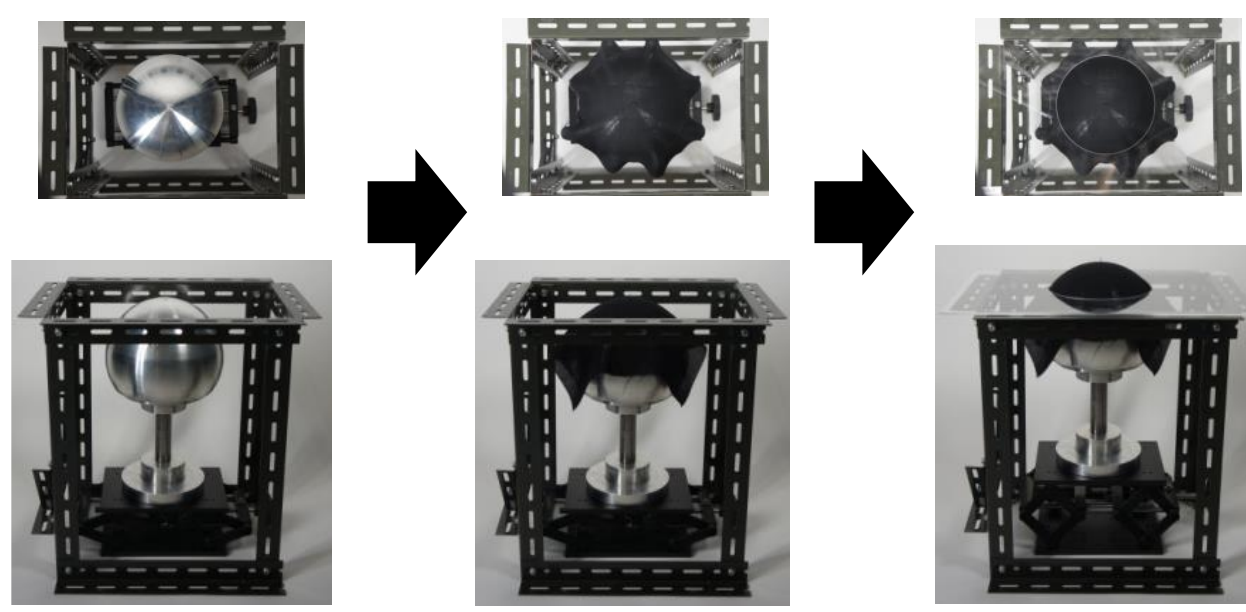

Figure 8. Measurement procedure.
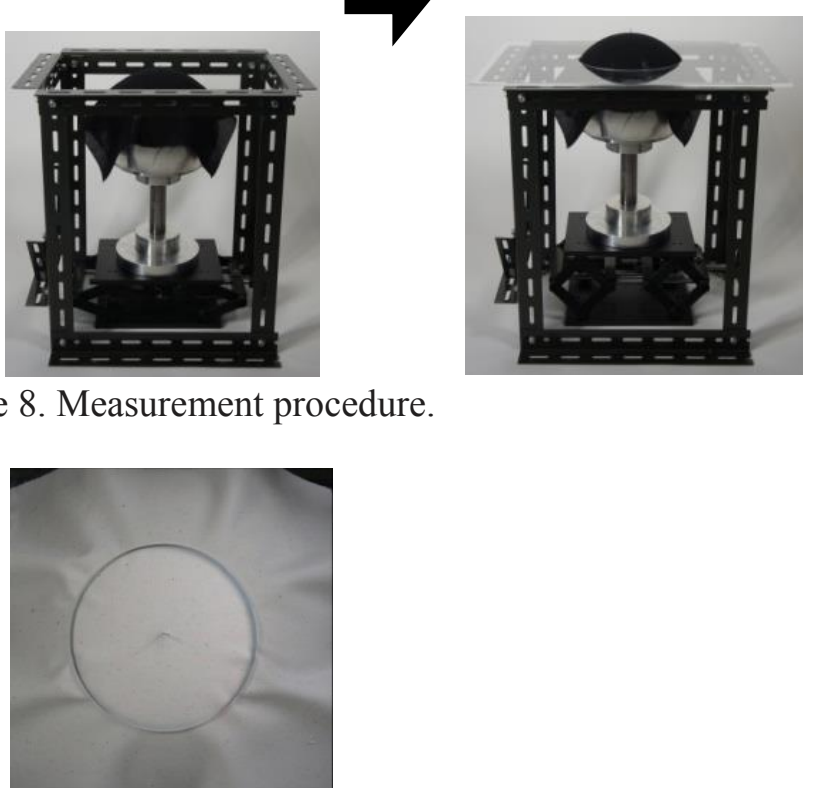

Figure 9. Wrinkling in the spherical crown.

\section{Measurement of structural and mechanical properties of fabric}

To investigate the relationship between the obtained fitting ability of fabric properties, the structural and mechanical properties of fabrics were measured. For structural properties, weave structure, weave density, mass per unit area, thickness, yarn count, cover factor and interlacing point density were measured. Thickness was measured under a constant load of 4.9 $\mathrm{Pa}$. Interlacing point density was obtained using equation (1):

$$
\text { Interlacing point density }=\text { warp density } \times \text { weft density } / \text { average float }
$$

where average float ${ }^{25}$ means the average floating number of yarn in the weave structure, as shown in Figure 10.

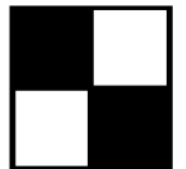

1

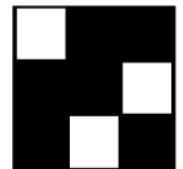

1.5

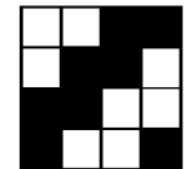

2

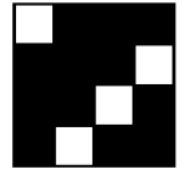

2

Figure 10. Average float ${ }^{25}$. 
The mechanical properties of fabric were measured using a KES-FB system ${ }^{26}$. Measurement items are shown in Table 1. Each sample had dimensions of $200 \mathrm{~mm} \times 200 \mathrm{~mm}$. The experiments were carried out five times for each property and sample with varying warp and weft directions. The mean values were calculated for all the results. The experiment was carried out under a temperature of $20^{\circ} \mathrm{C} \pm 1{ }^{\circ} \mathrm{C}$ and a relative humidity of $65 \% \pm 4 \%$.

Relationships between fitting ability and mechanical and structural properties were investigated by calculating correlation coefficients.

Table 1 Measurement items for the mechanical properties of fabric ${ }^{26}$

\begin{tabular}{|c|c|c|c|}
\hline Blocked Properties & Symbols & Characteristic value & Unit \\
\hline \multirow{4}{*}{ Tensile } & EM & Tensile strain & $\%$ \\
\hline & LT & Linearity & - \\
\hline & WT & Tensile energy & $\mathrm{gf} \cdot \mathrm{cm} / \mathrm{cm}^{2}$ \\
\hline & RT & Resilience & $\%$ \\
\hline \multirow{2}{*}{ Bending } & $\mathrm{B}$ & Bending rigidity & $\mathrm{gf} \cdot \mathrm{cm}^{2} / \mathrm{cm}$ \\
\hline & $2 \mathrm{HB}$ & Hysteresis & $\mathrm{gf} \cdot \mathrm{cm} / \mathrm{cm}$ \\
\hline \multirow{3}{*}{ Shearing } & $\mathrm{G}$ & Shear stiffness & $\mathrm{gf} / \mathrm{cm} \cdot$ degree \\
\hline & $2 \mathrm{HG}$ & Hysteresis at shear angle $0.5^{\circ}$ & $\mathrm{gf} / \mathrm{cm}$ \\
\hline & $2 \mathrm{HG} 5$ & Hysteresis at shear angle $5^{\circ}$ & $\mathrm{gf} / \mathrm{cm}$ \\
\hline \multirow{3}{*}{ Compression } & $\mathrm{LC}$ & Linearity & - \\
\hline & WC & Compressional energy & $\mathrm{gf} \cdot \mathrm{cm} / \mathrm{cm}^{2}$ \\
\hline & $\mathrm{RC}$ & Resilience & $\%$ \\
\hline \multirow{3}{*}{ Surface } & MIU & Coefficient of friction & - \\
\hline & MMD & Mean deviation of MIU & - \\
\hline & SMD & Geometrical roughness & micron \\
\hline
\end{tabular}

Experimental sample

19 kinds of fabric and one type of paper (copier paper) for comparison were investigated. Table 2 shows specifications of the samples. The mechanical properties of samples are shown in Appendix 3-6.

Table 2 Specification of sample

\begin{tabular}{|c|c|c|c|c|c|c|c|c|c|c|c|c|}
\hline Sample & Material & Note & Weave & $\begin{array}{l}\text { Warp weave } \\
\text { density }(/ \mathrm{cm})\end{array}$ & $\begin{array}{l}\text { Weft weave } \\
\text { density }(/ \mathrm{cm})\end{array}$ & $\begin{array}{c}\text { Mass per } \\
\text { unit area } \\
\left(\mathrm{g} / \mathrm{m}^{2}\right)\end{array}$ & $\begin{array}{c}\text { Thickness } \\
\text { (mm) }\end{array}$ & $\begin{array}{l}\text { Warp } \\
\text { yarn } \\
\text { count } \\
\text { (tex) }\end{array}$ & $\begin{array}{c}\text { Weft } \\
\text { yarn } \\
\text { count } \\
\text { (tex) }\end{array}$ & $\begin{array}{l}\text { Warp } \\
\text { cover } \\
\text { factor }\end{array}$ & $\begin{array}{l}\text { Weft } \\
\text { cover } \\
\text { factor }\end{array}$ & $\begin{array}{c}\text { Interlacing } \\
\text { point } \\
\text { density }\end{array}$ \\
\hline $\mathrm{A}$ & Cotton & Sheeting & Plain & 25 & 22 & 130.1 & 0.51 & 28 & 28 & 13 & 12 & 5.6 \\
\hline B & Cotton & Sheeting & Plain & 27 & 23 & 158.6 & 0.68 & 30 & 30 & 15 & 12 & 6.2 \\
\hline $\mathrm{C}$ & Wool & $-x^{2}$ & 1/2 Twill & 21 & 21 & 179.8 & 0.58 & 35 & 35 & 13 & 13 & 3.0 \\
\hline $\mathrm{D}$ & Wool & wool gauze & Plain & 16 & 14 & 109.1 & 0.99 & 37 & 37 & 10 & 9 & 2.2 \\
\hline $\mathrm{E}$ & Wool & satin & 2/1Twill & 18 & 17 & 203.6 & 0.72 & 41 & 52 & 12 & 12 & 2.0 \\
\hline $\mathrm{F}$ & Cotton & $=$ & Plain & 33 & 31 & 84.8 & 0.41 & $7 \times 2$ & 10 & 12 & 10 & 10.4 \\
\hline $\mathrm{G}$ & Cotton & 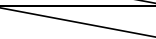 & Plain & 33 & 26 & 108.0 & 0.52 & $15 / / 2$ & 22 & 18 & 12 & 8.7 \\
\hline $\mathrm{H}$ & Cotton & 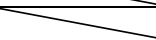 & Plain & 33 & 19 & 135.8 & 0.56 & $15 / / 2$ & $22 \times 2$ & 18 & 12 & 6.1 \\
\hline I & Cotton & 3 & 1/3 Twill & 33 & 39 & 93.9 & 0.48 & $7 \times 2$ & 10 & 12 & 12 & 6.5 \\
\hline $\mathrm{J}$ & Cotton & 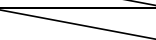 & Plain & 33 & 19 & 131.7 & 0.72 & $15 / / 2$ & $22 \times 2$ & 18 & 12 & 6.1 \\
\hline $\mathrm{K}$ & Wool & 3 & Plain & 27 & 25 & 137.4 & 0.35 & 30 & 27 & 15 & 13 & 6.9 \\
\hline $\mathrm{L}$ & Cotton & Sheeting & Plain & 30 & 29 & 113.2 & 0.47 & 23 & 17 & 14 & 12 & 8.7 \\
\hline $\mathrm{M}$ & Cotton & Sheeting & Plain & 19 & 19 & 129.0 & 0.71 & 33 & 37 & 11 & 11 & 3.6 \\
\hline $\mathrm{N}$ & Cotton & Sheeting & Plain & 28 & 26 & 83.5 & 0.48 & 17 & 16 & 11 & 10 & 7.3 \\
\hline $\mathrm{O}$ & Cotton & Sheeting & Plain & 29 & 20 & 94.8 & 0.44 & 19 & 21 & 13 & 9 & 5.9 \\
\hline $\mathrm{P}$ & Cotton & Sheeting & Plain & 29 & 24 & 101.7 & 0.48 & 19 & 21 & 13 & 11 & 7.1 \\
\hline Q & Cotton & Sheeting & Plain & 29 & 28 & 108.5 & 0.48 & 19 & 21 & 13 & 13 & 8.1 \\
\hline $\mathrm{R}$ & Cotton & -2 & 3/3 Twill & 30 & 22 & 264.4 & 0.82 & 43 & 53 & 19 & 16 & 2.2 \\
\hline $\mathrm{S}$ & Wool & -1 & $2 / 2$ Twill & 33 & 29 & 197.9 & 0.58 & 34 & 33 & 19 & 17 & 4.8 \\
\hline Paper & 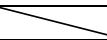 & copier paper & 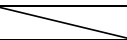 & 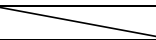 & & 66.6 & 0.09 & 7 & - & 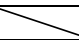 & 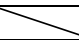 & 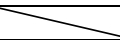 \\
\hline
\end{tabular}

\section{Results and discussion}

\section{Fitting ability of fabrics and effect of $R$ on the fitting ability}

Figure 11 shows the obtained mean $\theta_{\max }$ of each sample for different $R$ values. The range of the measured values was \pm 1 degree. Fabric samples showed wide range of $\theta_{\max }$, from 5 to 20 for $R=100 \mathrm{~mm}$, while $\theta_{\max }$ of paper was 1 degree. As expected, the obtained $\theta_{\max }$ were higher than the shear angles of available shear testers ${ }^{13,26}$. The $\theta_{\max }$ for $R$ $=75 \mathrm{~mm}$ and $65 \mathrm{~mm}$ were larger than those for $R=100 \mathrm{~mm}$ for the same fabrics. $\theta_{\max }$ of $R=63 \mathrm{~mm}$ was the largest among the three $R$. Ayada et al. ${ }^{21}$ concluded that the sphere size did not affect the fitting ability in their experiments. However, all fabric samples showed different $\theta_{\max }$ depending on $R$ in our experiments. This may be due to the occurrence of 
perceived wrinkles not only depending on $\theta_{\max }$ but also compressional displacement in the direction parallel to the sphere. The displacement is proportional to the length of the parallel, which is also proportional to $R$. $\theta_{\max }$ of $R=75 \mathrm{~mm}$ and $63 \mathrm{~mm}$ was calculated by multiplying measured $\theta_{\max }$ of $R=100$ and ratios of the radii $75 \mathrm{~mm}$ and $63 \mathrm{~mm} .1 .33$, the ratio of 100/75 and 1.59, one of 100/63 were used for the prediction. Figure 12 shows the relationship between predicted and measured $\theta_{\max }$ using the ratio of $R$. They showed a good agreement. Therefore, the surface fitting ability of smaller spheres was larger than that of larger ones, and the surface fitting ability of different spheres can be calculated from the results for a sphere using the ratio of the radii.

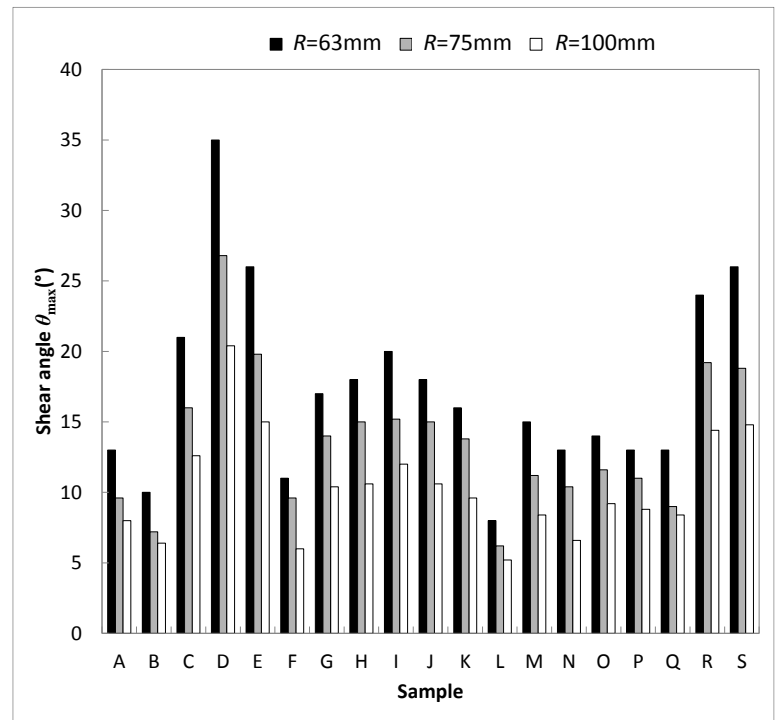

Figure 11. Comparison of shear angle $\theta_{\max }$ for different $R$.

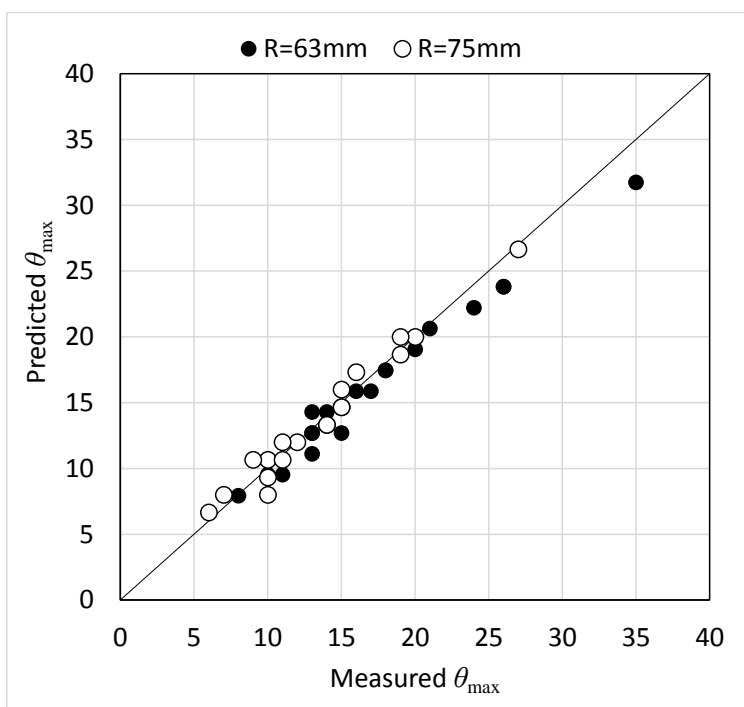

Figure 12. Comparison of $\theta_{\max }$ predicted from measured values of $R=100$ using ratios of the radii and measured ones.

\section{Relationship between fitting ability and mechanical and structural properties of fabric}

The relationships between the $\theta_{\max }$ of $R=100 \mathrm{~mm}$ and the structural and mechanical parameters of fabrics shown in Table 3 and Appendix 3-6 were examined. Table 4 shows the coefficients of correlation between $\theta_{\max }$ and the structural properties. The coefficients of correlation between $\theta_{\max }$ and interlacing point density were the highest, and the second highest was that between $\theta_{\max }$ and thickness. Table 4 shows the coefficients of correlation between $\theta_{\max }$ and mechanical properties. Among the mechanical properties, there are coefficients of correlation between almost all items of shear properties. Although thickness, interlacing point density and shear properties showed high correlation, it was still not possible to predict the surface fitting ability using a single parameter of a fabric.

Table 3 Coefficient of correlation between $\theta_{\max }$ and structure properties

\begin{tabular}{|l|l|}
\hline Properties & $\theta_{\max }(R=100 \mathrm{~mm})$ \\
\hline Warp weave density $(/ \mathrm{cm})$ & -0.41 \\
\hline Weft weave density $(/ \mathrm{cm})$ & -0.37 \\
\hline Average weave density $/ \mathrm{cm})$ & -0.43 \\
\hline Mass per unit area $\left(\mathrm{g} / \mathrm{m}^{2}\right)$ & $0.46^{*}$ \\
\hline Thickness $(\mathrm{mm})$ & $0.70^{* *}$ \\
\hline Warp yarn count $($ tex $)$ & $0.64^{* *}$ \\
\hline Weft yarn count $($ tex $)$ & $0.57^{*}$ \\
\hline Average yarn count $($ tex $)$ & $0.61^{* *}$ \\
\hline Warp cover factor & 0.05 \\
\hline Weft cover factor & 0.19 \\
\hline Average cover factor & 0.11 \\
\hline Interlacing point density & $-0.75^{* *}$ \\
\hline$* *$ Significant level $1 \%$, Significant level $5 \%$ &
\end{tabular}

**Significant level 1\%, *Significant level 5\% 
Table 4 Coefficient of correlation between $\theta_{\max }$ and mechanical properties

\begin{tabular}{|c|c|c|}
\hline Blocked properties & Symbols & $\theta_{\max }(R=100 \mathrm{~mm})$ \\
\hline \multirow{3}{*}{ Shear } & $\mathrm{G}($ mean $)$ & $-0.63^{* *}$ \\
\cline { 2 - 3 } & 2HG(mean) & $-0.64^{* *}$ \\
\cline { 2 - 3 } & 2HG5(mean) & $-0.66^{* *}$ \\
\hline \multirow{3}{*}{ Tensile } & LT(mean) & $-0.58^{* *}$ \\
\cline { 2 - 3 } & WT(mean) & 0.40 \\
\cline { 2 - 3 } & RT(mean) & 0.11 \\
\cline { 2 - 3 } & EMT(mean) & $0.57^{*}$ \\
\hline \multirow{2}{*}{ Bending } & B(mean) & 0.11 \\
\cline { 2 - 3 } & 2HB(mean) & $-0.46^{*}$ \\
\hline \multirow{3}{*}{ Compression } & LC & 0.20 \\
\cline { 2 - 3 } & WC & 0.50 \\
\cline { 2 - 3 } & RC & $0.57^{*}$ \\
\hline \multirow{3}{*}{ Surface } & MIU (mean) & -0.23 \\
\cline { 2 - 3 } & MMD(mean) & -0.26 \\
\cline { 2 - 3 } & SMD (mean) & -0.29 \\
\hline
\end{tabular}

**Significant level 1\%, *Significant level 5\%

\section{Prediction of fitting ability}

The relationships between the fitting ability and the fabric properties were analysed to predict the surface fitting ability with small numbers of properties. Multiple regression analysis with step wise method was applied to reduce the explanatory variables of the factors that have significant correlation with the fitting ability of $R=100 \mathrm{~mm}$. The equation (2) was obtained and the coefficient of correlation was 0.944.

$$
\theta_{\max }=14.9(\text { Thickness })-5.95(\mathrm{G})+0.929(2 \mathrm{HG} 5)+0.224(\mathrm{RC})-6.6315
$$

Among explanatory variables in equation (2), the effect of compression resilience (RC) was unclear. Therefore, we tried to find another equation of high coefficient of correlation. Shear rigidity, G, was used because it is primarily related to the shear deformation and the coefficients of correlation with other shear properties were high. Among the structural parameters, thickness and interlacing point density were selected.

Using these properties and a $\theta_{\max }$ of $R=100 \mathrm{~mm}$, after some trials, a high correlation equation (3) for predicting surface fitting ability by regression analysis was found.

$$
\theta_{\max }=7.89+6.95 \text { (Thickness / G) - 0.45(interlacing point density) }
$$

This equation indicates that with increasing thickness against shear stiffness $\mathrm{G}$, there is a larger fitting ability $\theta_{\max }$; for higher interlacing point density, there is a smaller fitting ability $\theta_{\max }$. When fabric thickness becomes thicker, in-plane compression on the surface side would be easier, so that wrinkles hardly appear. Small shear rigidity and small interlacing point density means that yarns are easy to move in the cross-section. The shear stiffness $\mathrm{G}$ is measured in shear angle between 0.5 and 5 degrees while $\theta_{\max }$ is higher than those angles. Thus, the thickness and interlacing point density are required to predict $\theta_{\max }$.

A comparison between predicted and measured $\theta_{\max }$ is shown in Figure 13. The correlation coefficient between predictive and measured values was 0.95 , which means it is useful for predicting surface fitting ability.

Ayada et al. ${ }^{22}$ proposed a prediction equation for fitting ability, equation (4).

$$
\log (a / R)=-0.2584-0.3875 \log (\mathrm{G}+2 \mathrm{HG} 5)-0.0537 \log (\mathrm{B}+\mathrm{HB})+0.0499 \log (\mathrm{EMT} / \mathrm{LT})
$$

Using equation (4), the fitting abilities of our 19 samples were calculated. A comparison of calculated and measured values is shown in Figure 14. The coefficients of correlation were 0.77 . Therefore, it is clear that equation (3) is more suitable for predicting the surface fitting ability of fabric in low tension. The range of mass per unit area $\left(\mathrm{g} / \mathrm{m}^{2}\right)$ of all samples are between 83.5 and 264.4 which are light and middle ranges of general apparel fabrics. Thus, the proposed equation will be useful for general apparel fabrics. 


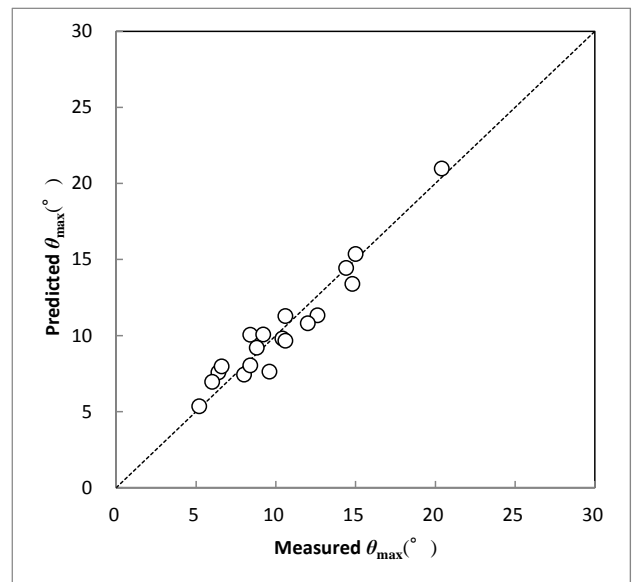

Figure 13. Comparison between predicted and measured $\theta_{\max }(R=100 \mathrm{~mm})$.

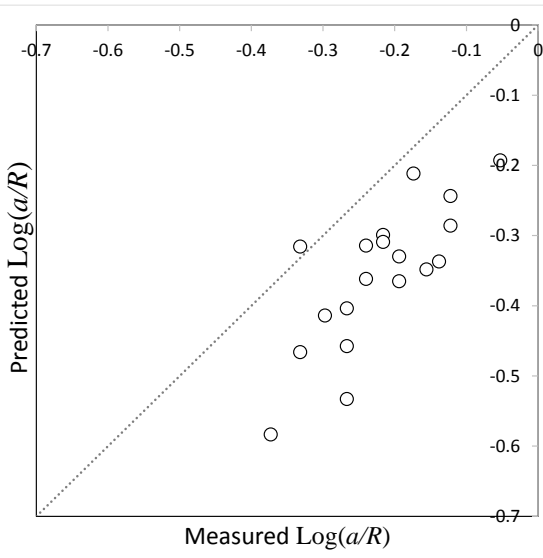

Figure 14. Comparison between predicted and measured $\log (a / R)(R=100 \mathrm{~mm})$ using Ayada's method $^{22}$.

\section{Conclusions}

A new method and testing equipment for the evaluation of the surface fitting ability of fabrics were developed. A quantity of the shear deformation limit $\theta_{\max }$ of a fabric covering a spherical surface without wrinkling when no external tensile load was applied as an index of surface fitting ability was regarded. Values of $\theta_{\max }$ for woven fabric in covering a sphere were calculated. Testing equipment with three spheres and plates with circular holes of varying radii corresponding to $\theta_{\max }$ were constructed. Using this equipment, we measured $\theta_{\max }$ for 19 woven fabrics. The relationship between $\theta_{\max }$ and sphere radii was also investigated. Using the proposed method, $\theta_{\max }$ was easily measured with small error. It is clear that the $\theta_{\max }$ of the same fabric differed depending on $R$ and was able to be predicted using the ratio of radii.

The correlations between $\theta_{\max }$ and each mechanical property and structural property of woven fabric were investigated. Thickness, interlacing point density and shear stiffness showed high correlation with $\theta_{\max }$. Using these properties, a new prediction equation for $\theta_{\max }$ was proposed. The predictive values showed a good agreement with the measured values.

Consequently, it was found that the surface fitting ability of woven fabrics is able to be predicted with structural and mechanical properties. The results will be useful for selecting fabric for making garments and interior items without wrinkles.

\section{Acknowledgements}

This work was supported by JSPS KAKENHI under grant numbers JP24220012 and JP16K16255.

\section{REFERENCES}

1. Shinohara, A. Ifuku no kikagaku (Geometry of clothes), Tokyo, Kouseikan, 2011, p.4, 24-42.

2. Shinohara, A. and Uchida S. The surface fitness of textile fabrics. J Text Machin Soc Jpn 1966; 19: T17-T23.

3. Shinohara A. A plain instruction on the geometry of clothing construction. J Text Machin Soc Jpn 1977; 30: P189P195

4. Moriguchi S and Sato K. Nunoji no kikagaku (Geometry of fabrics). Sugaku Seminar 1972; 8: 55-59.

5. Lindberg J, Waesterberg L and Svenson R. Wool fabrics as garment construction materials. $J$ Text Inst Trans 1960; 51: T1475-T1493.

6. Waesterberg L. Making-up properties of wool fabrics. $J$ Text Inst Trans 1965; 56: T517-T532.

7. Morooka $\mathrm{H}$ and Niwa M. Physical properties of fabrics relating to making-up and good appearance. J Text Machin Soc Jpn 1978; 24: 105-114.

8. Shishoo RL. Importance of mechanical and physical properties of fabrics in the clothing manufacturing process. Int J Cloth Sci Technol 1995; 7: 35-42.

9. Kawabata $\mathrm{S}$ and Niwa M. Fabric performance in clothing and clothing manufacture. J Text Inst 1989; 80: 19-50.

10. Mahar TJ, Dhingra RC and Postle R. Fabric mechanical and physical properties relevant to clothing manufacturePart 1: Fabric overfeed, formability, shear and hygral expansion during tailoring. Int J Cloth Sci Technol 1989; 1: $12-20$.

11. Mahar TJ, Ajiki I and Postle R. Fabric mechanical and physical properties relevant to clothing manufacture- Part 2: Structural balance, breaking elongation and curvature of seams. Int J Cloth Sci Technol 1989; 1: 5-10

12. Mahar TJ, Ajiki I, Dhingra RC and Postle R. Fabric mechanical and physical properties relevant to clothing manufacture- Part 3: Shape formation in tailoring. Int J Cloth Sci Technol 1989; 1:6-13

13. Bassett RJ. The biaxial tensile and shear properties of textile fabrics and their application to the study of fabric tailorability. PhD Thesis, University of New South Wales, Australia, 1981. 
14. Bassett RJ and Postle R. Fabric mechanical and physical properties: Part 4: The fitting of woven fabrics to a threedimensional surface. Int J Cloth Sci Technol 1990; 2:26-31

15. Hearle JWS, Grosberg P and Backer S. Structural mechanics of fibers, yarns, and fabrics. New York: WileyInterscience, 1969, p.372

16. Mack C and Taylor HM. The fitting of woven cloth to surfaces. J Text Inst Trans 1956; 47: T477-T488.

17. Heisey FL and Haller KD. Fitting woven fabric to surfaces in three dimensions. $J$ Text Inst 1988; 79: 250-263.

18. Takatera M, Shimizu Y and Shinohara A. Sphere surface construction with woven fabric polyhedron. Sen'i Gakkaishi 2003; 59: 76-79.

19. Shinohara A and Bao L. Wrapping method of sphere by a smocked woven fabric. Bull Shinshu Junior College 2010; 21: 1-5.

20. Treloar LRG. The effect of test-piece dimensions on the behaviour of fabrics in shear. $J$ Text Inst Trans 1965; 56: T533-T550.

21. Ayada M, Matsunawa M and Yamaguchi M. Fundamental studies on formability of cloths around curved surface Part 1: On distributions of regions of the contact between fabric and a curved surface. J Jpn Res Assoc Text EndUses 1984; 25: 364-370.

22. Ayada M. Fundamental studies on formability of clothes around curved surface Part 2: The relations between formability and mechanical properties of fabrics. J Jpn Res Assoc Text End-Uses 1988; 29: 444-450.

23. Cho Y, Komatsu T, Inui S, Takatera M, Shimizu Y and Park H. Individual pattern making using computerized draping method for clothing. Text Res $J$ 2006; 76: 646-654.

24. Aoyama $\mathrm{K}$ and Shimazaki K. A study on easing by a variable top feed and differential drop feed sewing machine -Applications of computerized sewing to easing in sleeve cap seam. Sen'i Gakkaishi 2008; 64: 313-318.

25. Malčiauskiene E, Milašius A, Laureckienė G and Milašius R. Influence of weave into slippage of yarns in woven fabric. Mater Sci (Medžiagotyra) 2011; 17: 47-51.

26. Kawabata S. The standardization and analysis of hand evaluation. 2nd ed. Osaka: Textile Machinery Society of Japan, 1980.

\section{Appendix}

Appendix 1 Hole radius $r$ per shear angle of $1^{\circ}$ for experimental spheres of $R=75$ and $100 \mathrm{~mm}$

\begin{tabular}{|c|c|c|c|c|}
\hline$\theta_{45}\left({ }^{\circ}\right)$ & Polar angle & $r / R$ & \multicolumn{2}{|c|}{$r(\mathrm{~mm})$ at $R=75 \mathrm{~mm} r(\mathrm{~mm})$ at $R=100 \mathrm{~mm}$} \\
\hline 1 & 10.7 & 0.186 & 14.0 & 18.6 \\
\hline 2 & 15.2 & 0.263 & 19.7 & 26.3 \\
\hline 3 & 18.7 & 0.320 & 24.0 & 32.0 \\
\hline 4 & 21.7 & 0.369 & 27.7 & 36.9 \\
\hline 5 & 24.3 & 0.411 & 30.8 & 41.1 \\
\hline 6 & 26.7 & 0.449 & 33.7 & 44.9 \\
\hline 7 & 28.9 & 0.483 & 36.2 & 48.3 \\
\hline 8 & 31.0 & 0.515 & 38.6 & 51.5 \\
\hline 9 & 33.0 & 0.544 & 40.8 & 54.4 \\
\hline 10 & 34.8 & 0.571 & 42.8 & 57.1 \\
\hline 11 & 36.7 & 0.597 & 44.7 & 59.7 \\
\hline 12 & 38.4 & 0.621 & 46.5 & 62.1 \\
\hline 13 & 40.0 & 0.643 & 48.3 & 64.3 \\
\hline 14 & 41.7 & 0.665 & 49.9 & 66.5 \\
\hline 15 & 43.2 & 0.685 & 51.4 & 68.5 \\
\hline 16 & 44.8 & 0.705 & 52.9 & 70.5 \\
\hline 17 & 46.3 & 0.723 & 54.2 & 72.3 \\
\hline 18 & 47.8 & 0.741 & 55.6 & 74.1 \\
\hline 19 & 49.2 & 0.757 & 56.8 & 75.7 \\
\hline 20 & 50.7 & 0.774 & 58.0 & 77.4 \\
\hline 21 & 52.1 & 0.789 & 59.1 & 78.9 \\
\hline 22 & 53.4 & 0.803 & 60.2 & 80.3 \\
\hline 23 & 54.8 & 0.817 & 61.3 & 81.7 \\
\hline 24 & 56.1 & 0.830 & 62.3 & 83.0 \\
\hline 25 & 57.5 & 0.843 & 63.2 & 84.3 \\
\hline 26 & 58.8 & 0.855 & 64.1 & 85.5 \\
\hline 27 & 60.0 & 0.866 & 65.0 & 86.6 \\
\hline 28 & 61.3 & 0.877 & 65.8 & 87.7 \\
\hline 29 & 62.6 & 0.888 & 66.6 & 88.8 \\
\hline 30 & 63.9 & 0.898 & 67.3 & 89.8 \\
\hline
\end{tabular}


Appendix 2 Relationship between hole radius $r$ and corresponding value of maximum shear angle for experimental sphere of $R=63 \mathrm{~mm}$

\begin{tabular}{|c|c|c|c|}
\hline$r(\mathrm{~mm})$ & Shear angle $\theta_{45}\left(^{\circ}\right)$ & $r(\mathrm{~mm})$ & Shear angle $\theta_{45}\left({ }^{\circ}\right)$ \\
\hline 14.0 & 1.4 & 48.3 & 19.5 \\
\hline 18.6 & 2.5 & 49.9 & 21.2 \\
\hline 19.7 & 2.9 & 51.4 & 22.9 \\
\hline 24.0 & 4.3 & 51.5 & 23.0 \\
\hline 26.3 & 5.1 & 52.9 & 24.7 \\
\hline 27.7 & 5.7 & 54.2 & 26.5 \\
\hline 30.8 & 7.2 & 54.4 & 26.7 \\
\hline 32.0 & 7.8 & 55.6 & 28.4 \\
\hline 33.7 & 8.7 & 56.8 & 30.4 \\
\hline 36.2 & 10.1 & 57.1 & 30.9 \\
\hline 36.9 & 10.6 & 58.0 & 32.6 \\
\hline 38.6 & 11.7 & 59.1 & 35.0 \\
\hline 40.8 & 13.9 & 59.7 & 36.1 \\
\hline 41.1 & 13.4 & 60.2 & 37.6 \\
\hline 42.8 & 14.7 & 61.3 & 40.7 \\
\hline 44.7 & 16.3 & 61.6 & 41.8 \\
\hline 44.9 & 16.4 & 62.1 & 43.7 \\
\hline 46.5 & 17.9 & 62.3 & 44.8 \\
\hline
\end{tabular}

Appendix 3 Tensile properties of samples

\begin{tabular}{|c|c|c|c|c|c|c|c|c|c|c|c|c|}
\hline $\begin{array}{l}\text { Samp } \\
\text { le }\end{array}$ & $\begin{array}{l}\text { LT } \\
\text { (warp) }\end{array}$ & $\begin{array}{l}\text { LT } \\
\text { (weft) }\end{array}$ & $\begin{array}{l}\text { LT } \\
\text { (mean) }\end{array}$ & $\begin{array}{l}\text { WT } \\
\text { (warp) }\end{array}$ & $\begin{array}{l}\text { WT } \\
\text { (weft) }\end{array}$ & $\begin{array}{l}\text { WT } \\
\text { (mean) }\end{array}$ & $\begin{array}{l}\text { RT } \\
\text { (warp) }\end{array}$ & $\begin{array}{l}\text { RT } \\
\text { (weft) }\end{array}$ & $\begin{array}{l}\text { RT } \\
\text { (mean) }\end{array}$ & $\begin{array}{l}\text { EMT } \\
\text { (warp) }\end{array}$ & $\begin{array}{l}\text { EMT } \\
\text { (weft) }\end{array}$ & $\begin{array}{l}\text { EMT } \\
\text { (mean) } \\
\end{array}$ \\
\hline A & 0.843 & 0.748 & 0.795 & 4.04 & 11.29 & 7.67 & 75.27 & 54.80 & 65.04 & 1.92 & 6.04 & 3.98 \\
\hline $\mathrm{B}$ & 0.824 & 0.727 & 0.776 & 4.60 & 30.08 & 17.34 & 72.18 & 41.32 & 56.75 & 2.23 & 16.54 & 9.39 \\
\hline $\mathrm{C}$ & 0.756 & 0.757 & 0.756 & 8.62 & 10.40 & 9.51 & 70.31 & 70.59 & 70.45 & 4.56 & 5.49 & 5.03 \\
\hline $\mathrm{D}$ & 0.569 & 0.587 & 0.578 & 14.83 & 13.55 & 14.19 & 54.50 & 53.51 & 54.00 & 10.43 & 9.24 & 9.84 \\
\hline $\bar{E}$ & 0.619 & 0.553 & 0.586 & 8.23 & 16.13 & 12.18 & 64.80 & 56.05 & 60.43 & 5.32 & 11.67 & 8.49 \\
\hline $\mathrm{F}$ & 0.629 & 0.606 & 0.617 & 10.25 & 10.03 & 10.14 & 52.89 & 49.76 & 51.32 & 6.52 & 6.63 & 6.58 \\
\hline $\mathrm{G}$ & 0.594 & 0.580 & 0.587 & 6.08 & 9.95 & 8.02 & 59.70 & 48.24 & 53.97 & 4.09 & 6.87 & 5.48 \\
\hline $\mathrm{H}$ & 0.545 & 0.577 & 0.561 & 8.66 & 9.30 & 8.98 & 52.45 & 48.93 & 50.69 & 6.36 & 6.44 & 6.40 \\
\hline $\mathrm{I}$ & 0.557 & 0.537 & 0.547 & 7.40 & 11.34 & 9.37 & 54.47 & 46.39 & 50.43 & 5.32 & 8.44 & 6.88 \\
\hline $\mathrm{J}$ & 0.555 & 0.595 & 0.575 & 9.01 & 10.07 & 9.54 & 53.29 & 52.94 & 53.11 & 6.50 & 6.77 & 6.64 \\
\hline $\mathrm{K}$ & 0.722 & 0.683 & 0.703 & 7.23 & 14.84 & 11.04 & 76.49 & 69.52 & 73.01 & 4.01 & 8.69 & 6.35 \\
\hline $\mathrm{L}$ & 0.877 & 0.795 & 0.836 & 5.02 & 10.06 & 7.54 & 65.98 & 56.08 & 61.03 & 2.29 & 5.06 & 3.68 \\
\hline $\mathrm{M}$ & 0.751 & 0.722 & 0.737 & 9.32 & 9.24 & 9.28 & 51.44 & 54.04 & 52.74 & 4.97 & 5.12 & 5.04 \\
\hline $\mathrm{N}$ & 0.834 & 0.746 & 0.790 & 5.38 & 8.63 & 7.01 & 62.70 & 55.40 & 59.05 & 2.58 & 4.63 & 3.61 \\
\hline $\mathrm{O}$ & 0.683 & 0.593 & 0.638 & 6.94 & 15.96 & 11.45 & 50.59 & 37.16 & 43.88 & 4.06 & 10.77 & 7.42 \\
\hline $\mathrm{P}$ & 0.678 & 0.659 & 0.669 & 7.03 & 13.86 & 10.45 & 51.65 & 41.45 & 46.55 & 4.15 & 8.41 & 6.28 \\
\hline Q & 0.695 & 0.704 & 0.700 & 6.65 & 13.43 & 10.04 & 54.01 & 42.45 & 48.23 & 3.83 & 7.63 & 5.73 \\
\hline $\mathrm{R}$ & 0.660 & 0.586 & 0.623 & 8.17 & 32.46 & 20.32 & 62.44 & 49.53 & 55.99 & 4.95 & 22.15 & 13.55 \\
\hline $\mathrm{S}$ & 0.657 & 0.653 & 0.655 & 11.92 & 9.54 & 10.73 & 65.41 & 64.30 & 64.85 & 7.27 & 5.85 & 6.56 \\
\hline
\end{tabular}

Appendix 4 Shear properties of samples

\begin{tabular}{|c|c|c|c|c|c|c|c|c|c|}
\hline Sample & G(warp) & $\mathrm{G}$ (weft) & $\mathrm{G}($ mean $)$ & 2HG (warp) & 2HG (weft) & 2HG (mean) & 2HG5 (warp) & 2HG5 (weft) & 2HG5 (mean) \\
\hline $\mathrm{A}$ & 1.73 & 1.68 & 1.71 & 2.19 & 2.67 & 2.43 & 6.17 & 6.17 & 6.17 \\
\hline $\mathrm{B}$ & 2.05 & 1.77 & 1.91 & 2.37 & 2.41 & 2.39 & 4.38 & 4.56 & 4.47 \\
\hline $\mathrm{C}$ & 0.85 & 0.84 & 0.84 & 1.18 & 1.09 & 1.13 & 2.03 & 1.92 & 1.98 \\
\hline $\mathrm{D}$ & 0.56 & 0.41 & 0.49 & 0.85 & 0.79 & 0.82 & 0.96 & 0.83 & 0.90 \\
\hline$E$ & 0.66 & 0.53 & 0.60 & 1.11 & 1.03 & 1.07 & 1.63 & 1.44 & 1.53 \\
\hline $\mathrm{F}$ & 0.82 & 0.72 & 0.77 & 1.35 & 1.14 & 1.24 & 2.23 & 2.01 & 2.12 \\
\hline $\mathrm{G}$ & 0.66 & 0.59 & 0.63 & 0.99 & 1.31 & 1.15 & 1.74 & 1.98 & 1.86 \\
\hline $\mathrm{H}$ & 0.81 & 0.91 & 0.86 & 1.61 & 1.90 & 1.76 & 2.61 & 2.83 & 2.72 \\
\hline $\mathrm{I}$ & 0.54 & 0.61 & 0.58 & 0.62 & 0.90 & 0.76 & 0.93 & 1.17 & 1.05 \\
\hline $\mathrm{J}$ & 0.86 & 0.78 & 0.82 & 1.43 & 1.36 & 1.40 & 2.19 & 2.08 & 2.13 \\
\hline $\mathrm{K}$ & 0.88 & 0.85 & 0.87 & 0.93 & 1.05 & 0.99 & 1.76 & 1.79 & 1.77 \\
\hline $\mathrm{L}$ & 2.38 & 2.41 & 2.39 & 4.80 & 4.49 & 4.65 & 7.94 & 7.72 & 7.83 \\
\hline $\mathrm{M}$ & 1.25 & 1.36 & 1.31 & 2.68 & 2.82 & 2.75 & 3.86 & 4.09 & 3.98 \\
\hline $\mathrm{N}$ & 0.94 & 1.02 & 0.98 & 1.82 & 2.08 & 1.95 & 2.94 & 3.10 & 3.02 \\
\hline $\mathrm{O}$ & 0.62 & 0.65 & 0.64 & 1.25 & 1.49 & 1.37 & 2.11 & 2.28 & 2.20 \\
\hline $\mathrm{P}$ & 0.72 & 0.77 & 0.74 & 1.52 & 1.85 & 1.68 & 2.78 & 2.95 & 2.86 \\
\hline $\mathrm{Q}$ & 0.94 & 0.83 & 0.88 & 1.83 & 2.02 & 1.93 & 3.55 & 3.57 & 3.56 \\
\hline $\mathrm{R}$ & 0.87 & 0.64 & 0.76 & 1.48 & 1.09 & 1.29 & 2.68 & 2.02 & 2.35 \\
\hline $\mathrm{S}$ & 0.57 & 0.49 & 0.53 & 0.88 & 0.77 & 0.82 & 1.29 & 1.19 & 1.24 \\
\hline
\end{tabular}


Appendix 5 Bending and compressive properties of samples

\begin{tabular}{|c|c|c|c|c|c|c|c|c|c|}
\hline Sample & B (warp) & B (weft) & B (mean) & 2HB (warp) & 2HB (weft) & 2HB (mean) & LC & WC & RC \\
\hline A & 0.161 & 0.063 & 0.112 & 0.119 & 0.045 & 0.082 & 0.339 & 0.157 & 50.58 \\
\hline B & 0.083 & 0.050 & 0.067 & 0.064 & 0.033 & 0.049 & 0.360 & 0.255 & 46.72 \\
\hline C & 0.131 & 0.091 & 0.111 & 0.049 & 0.035 & 0.042 & 0.363 & 0.147 & 65.70 \\
\hline D & 0.061 & 0.055 & 0.058 & 0.021 & 0.020 & 0.021 & 0.360 & 0.470 & 59.36 \\
\hline E & 0.141 & 0.103 & 0.122 & 0.047 & 0.038 & 0.043 & 0.372 & 0.210 & 63.79 \\
\hline F & 0.037 & 0.022 & 0.029 & 0.024 & 0.015 & 0.020 & 0.304 & 0.188 & 50.58 \\
\hline G & 0.040 & 0.033 & 0.037 & 0.025 & 0.028 & 0.026 & 0.286 & 0.169 & 49.21 \\
\hline H & 0.041 & 0.066 & 0.053 & 0.028 & 0.051 & 0.039 & 0.320 & 0.169 & 50.00 \\
\hline I & 0.033 & 0.023 & 0.028 & 0.015 & 0.011 & 0.013 & 0.281 & 0.164 & 54.67 \\
\hline J & 0.040 & 0.066 & 0.053 & 0.027 & 0.033 & 0.030 & 0.316 & 0.275 & 46.77 \\
\hline K & 0.054 & 0.046 & 0.050 & 0.014 & 0.007 & 0.011 & 0.389 & 0.059 & 65.31 \\
\hline L & 0.161 & 0.045 & 0.103 & 0.189 & 0.059 & 0.124 & 0.310 & 0.154 & 45.39 \\
\hline M & 0.103 & 0.064 & 0.084 & 0.126 & 0.072 & 0.099 & 0.292 & 0.209 & 44.41 \\
\hline N & 0.108 & 0.034 & 0.071 & 0.109 & 0.034 & 0.071 & 0.319 & 0.167 & 43.87 \\
\hline O & 0.047 & 0.020 & 0.033 & 0.035 & 0.015 & 0.025 & 0.329 & 0.134 & 47.31 \\
\hline P & 0.040 & 0.027 & 0.034 & 0.037 & 0.023 & 0.030 & 0.307 & 0.148 & 45.54 \\
\hline Q & 0.042 & 0.035 & 0.039 & 0.042 & 0.032 & 0.037 & 0.302 & 0.151 & 45.80 \\
\hline R & 0.110 & 0.078 & 0.094 & 0.050 & 0.040 & 0.045 & 0.300 & 0.189 & 49.17 \\
\hline S & 0.059 & 0.051 & 0.055 & 0.018 & 0.017 & 0.017 & 0.292 & 0.119 & 52.02 \\
\hline
\end{tabular}

Appendix 6 Surface properties of samples

\begin{tabular}{|c|c|c|c|c|c|c|c|c|c|}
\hline Sample & MIU(warp) & MIU (weft) & MIU (mean) & MMD(warp) & MMD (weft) & MMD (mean) & SMD (warp) & SMD (weft) & SMD (mean) \\
\hline A & 0.144 & 0.027 & 0.085 & 0.0213 & 0.0065 & 0.0139 & 4.11 & 0.44 & 2.28 \\
\hline B & 0.165 & 0.004 & 0.084 & 0.0162 & 0.0020 & 0.0091 & 2.96 & 0.30 & 1.63 \\
\hline $\mathrm{C}$ & 0.138 & 0.021 & 0.079 & 0.0163 & 0.0032 & 0.0098 & 2.60 & 0.25 & 1.42 \\
\hline $\mathrm{D}$ & 0.192 & 0.007 & 0.099 & 0.0163 & 0.0020 & 0.0091 & 9.42 & 0.99 & 5.21 \\
\hline $\mathrm{E}$ & 0.158 & 0.008 & 0.083 & 0.0155 & 0.0010 & 0.0082 & 2.76 & 0.22 & 1.49 \\
\hline $\mathrm{F}$ & 0.158 & 0.166 & 0.162 & 0.0080 & 0.0087 & 0.0084 & 4.48 & 4.51 & 4.49 \\
\hline $\mathrm{G}$ & 0.188 & 0.187 & 0.187 & 0.0108 & 0.0117 & 0.0113 & 5.69 & 11.28 & 8.49 \\
\hline $\mathrm{H}$ & 0.198 & 0.175 & 0.186 & 0.0383 & 0.0124 & 0.0254 & 9.46 & 8.62 & 9.04 \\
\hline I & 0.174 & 0.160 & 0.167 & 0.0117 & 0.0056 & 0.0086 & 3.26 & 2.15 & 2.70 \\
\hline $\mathrm{J}$ & 0.198 & 0.182 & 0.190 & 0.0423 & 0.0118 & 0.0271 & 9.99 & 7.95 & 8.97 \\
\hline $\mathrm{K}$ & 0.144 & 0.135 & 0.139 & 0.0174 & 0.0172 & 0.0173 & 6.90 & 9.63 & 8.26 \\
\hline $\mathrm{L}$ & 0.159 & 0.157 & 0.158 & 0.0174 & 0.0172 & 0.0173 & 6.90 & 9.63 & 8.26 \\
\hline M & 0.178 & 0.174 & 0.176 & 0.0164 & 0.0143 & 0.0154 & 14.68 & 12.87 & 13.77 \\
\hline $\mathrm{N}$ & 0.156 & 0.152 & 0.154 & 0.0152 & 0.0171 & 0.0161 & 8.05 & 7.81 & 7.93 \\
\hline $\mathrm{O}$ & 0.148 & 0.149 & 0.148 & 0.0116 & 0.0106 & 0.0111 & 7.59 & 5.46 & 6.52 \\
\hline $\mathrm{P}$ & 0.154 & 0.152 & 0.153 & 0.0092 & 0.0093 & 0.0093 & 6.66 & 4.88 & 5.77 \\
\hline Q & 0.150 & 0.151 & 0.150 & 0.0076 & 0.0089 & 0.0082 & 5.36 & 4.89 & 5.13 \\
\hline $\mathrm{R}$ & 0.175 & 0.172 & 0.173 & 0.0076 & 0.0071 & 0.0074 & 2.71 & 3.29 & 3.00 \\
\hline $\mathrm{S}$ & 0.142 & 0.150 & 0.146 & 0.0076 & 0.0102 & 0.0089 & 4.03 & 3.68 & 3.86 \\
\hline
\end{tabular}

